\title{
H-Complexes on the Basis of Macroheterocycles. 3. Solvation State of Tetra(3,5-di-tert-butylphenyl)porphin in Solutions ${ }^{\otimes}$
}

\author{
Viktor V. Aleksandriiskii, ${ }^{a, b} @$ Mikhail K. Islyaikin, ${ }^{a}$ Vladimir A. Burmistrov, ${ }^{\mathrm{a}, \mathrm{b}}$ and \\ Sergey A. Syrbu ${ }^{\mathrm{a}}$ \\ a'Ivanovo State University of Chemistry and Technology, Ivanovo, 153000, Russia \\ ${ }^{\mathrm{b}}$ Institute of Solution Chemistry of Russian Academy of Sciences, Ivanovo, 153045, Russia \\ @Corresponding author E-mail: NMR@isuct.ru
}

Using ${ }^{1} H$ NMR spectroscopy and semiempirical calculations (AM1) the solvation state of tetra(3,5-di-tert-butylphenyl) porphin (I) was studied in the binary mixtures, containing electrondonating solvating solvent and $\mathrm{CCl}_{4}$. The stability constants and thermodynamic characteristics of octasubstituted tetraphenylporphin H-complexes with electrondonating solvents were calculated on the basis of concentration and temperature dependencies of chemical shifts of the inner macrocyclic protons. The results of the spectroscopic study are discussed in a view of peculiarities of spatial and electronic structure of tetraphenylporphin (II) and its complexes, revealed by semiempirical method (AM1).

Keywords: Porphyrins, H-complex, solvation, ${ }^{1} \mathrm{H}$ NMR spectroscopy, AM1 method, stability constant.

\section{Н-Комплексы с участием макрогетероциклов. 3. Сольватационное состояние тетра(3,5-Аи-треm-бутилфенил) порфина в растворах}

\author{
B.В. Александрийский, ${ }^{\mathrm{a}, \mathrm{b}} @$ M.К. Исляйкин, ${ }^{a}$ B.А. Бурмистров, ${ }^{\mathrm{a}, \mathrm{b}}$ C.А. Сырбуа \\ а Ивановский государственный химико-технологический университет, Иваново, 153000, Россия \\ 'Институт химии растворов РАН, Иваново, 153045, Россия \\ @E-mail: NMR@isuct.ru
}

\begin{abstract}
Методами ${ }^{1}$ Н ЯМР спектроскопии и полуэмпирических квантово-химических расчетов (АМ1) изучено сольватационное состояние тетра(3,5-ди-трет-бутилфенил)порфина (I) в бинарных смесях, содержащих электронодонорный сольватируюший растворитель и тетрахлорметан. На основании концентрационных и температурных зависимостей химических сдвигов внутрициклических протонов октазамещенного тетрафенилпорфина рассчитаны константы устойчивости и термодинамические характеристики Н-комплексов с электронодонорныли растворителями. Результаты спектральных исследований обсуждены с учетом особенностей пространственного и электронного строения тетрафенилпорфина (II) и его комплексов, выявленных с помощью полуэмпирического метода АМ1.
\end{abstract}

Ключевые слова: Порфирины, Н-комплекс, сольватация, ${ }^{1} \mathrm{H}$ ЯМР спектроскопия, метод АМ1, константа устойчивости.

\section{Введение}

Реакционная способность макрогетероциклов (порфиринов, фталоцианинов и их аналогов) в растворах во многом определяется их ассоциативным и сольватационным состоянием. ${ }^{[1,2]}$ В особенности это касается реакции образования металлокомплексов, для которых влияние сольватации на состояние реакционного центра

${ }_{\otimes}$ Parts 1 and 2 see Ref. [4,5]
- внутрициклической полости - представляется крайне существенным, ${ }^{[3]}$ учитывая, что обязательной предварительной стадией комплексообразования является деформация и ионизация связей $-\mathrm{N}-\mathrm{H}$ макроциклов. ${ }^{[1]}$

В предыдущих работах ${ }^{[4,5]}$ нами было исследовано сольватационное и конформационное состояние стереохимически нежесткого трет-бутилзамещенного дибензолдиизоиндолмакрогетероцикла в бинарных сме- 
сях, содержащих электронодонорный сольватирующий компонент. Была обнаружена высокая селективность макроцикла по отношению к связыванию электронодоноров, содержащих карбонильные и тиокарбонильные группы.

Между тем проблемы специфической сольватации реакционных центров чрезвычайно важны не только для синтетических макрогетероциклов и их металлокомплексов, но и в случае биологических порфиринов и их аналогов. ${ }^{[3,6]}$

На сегодняшний день известны многочисленные исследования сольватации порфиринов методами изотермического насыщения по растворимости макроциклов и их комплексов, ${ }^{[7]}$ калориметрии, ${ }^{[8]}$ денсиметрии и термогравиметрии. ${ }^{[8,9]}$

Однако сложность интерпретации полученных результатов, связанная с получением в этих экспериментах лишь интегральных откликов на совокупность процессов, протекающих при взаимодействии макрогетеро-циклов и растворителей и многофакторным влиянием заместителей на энергию кристаллической решетки, конформационного состояния, образования полости растворителя и собственно сольватацию, не позволяет сделать обоснованные выводы по структуре сольватов.

Дополнительным фактором, затрудняющим изучение таких систем, является крайне низкая растворимость порфиринов, фталоцианинов и их аналогов. В результате структурной модификации ${ }^{[10]}$ удается получать замещенные порфирины, обладающие хорошей растворимостью в органических растворителях.

В связи с этим представляет интерес исследование сольватации таких порфиринов с использованием спектроскопии ЯМР, поскольку этот метод дает возможность наблюдать проявления специфических взаимодействий в химических сдвигах функциональных групп участников Н-связи. ${ }^{[11]}$

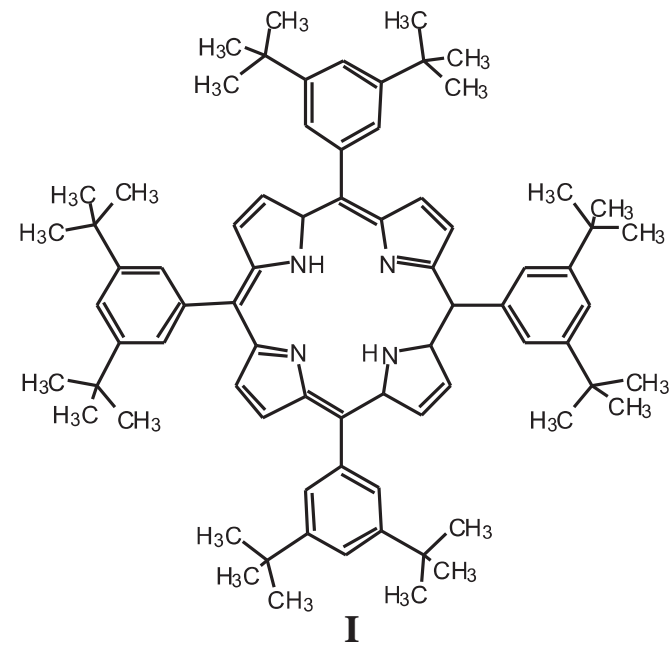

В работе были изучены ${ }^{1} \mathrm{H}$ ЯМР спектры тетра(3,5ди-трет-бутилфенил)порфина (I) в смешанных системах на основе тетрахлорметана (ТХМ) с добавкой электронодонорных (ЭД) растворителей: ацетона (АЦ), ацетонитрила (АН), пиридина (П), диметилформамида (ДМФА), диметилсульфоксида (ДМСО), диметилацетамида (ДМАА), 1,4-диоксана (ДО).

\section{Экспериментальная часть}

Тетра(3,5-ди-трет-бутилфенил)порфин (I) получен и очищен в соответствии с методикой описанной ранее. ${ }^{[10]} \mathrm{Pac}-$ творители очищали по стандартным методикам. ${ }^{[12]}$

Спектры ${ }^{1} \mathrm{H}$ ЯМР записывали с использованием спектрометра Bruker AC-200, снабженного температурной приставкой BVT-3000. Отсчет химических сдвигов (ХC) производили от внутреннего стандарта гексаметилдисилоксан ГМДСО $(0,055$ м.д.) с точностью 0,01 м.д.

\section{Обсуждение результатов}

В Таблице 1 представлены химические сдвиги протонов тетра(3,5-ди-трет-бутилфенил)порфина в различных растворителях и приведены изменения ХС при переходе от ТХМ к электронодонорному (ЭД) растворителю: $\Delta \delta=\left(\delta-\delta_{\mathrm{TXM}}\right)$.

Таблица 1. Химические сдвиги ${ }^{1} \mathrm{H}$ (м.д.) тетра(3,5-ди-третбутилфенил)порфина $(\mathrm{C}=0,01 \mathrm{M})$ при $298 \mathrm{~K}$.

\begin{tabular}{cccccc}
\hline \multirow{2}{*}{ растворитель } & \multirow{5}{c}{$\delta_{\beta}$} & \multicolumn{2}{c}{$\delta_{\mathrm{Ph}}$} & $\delta_{t-\mathrm{Bu}}$ & $\delta_{\mathrm{NH}}$ \\
\cline { 3 - 5 } & & opmo- & napa- & & \\
\hline ТХМ & 8,80 & 8,06 & 7,71 & 1,54 & $-2,75$ \\
\hline ДМСО & 8,83 & 8,02 & 7,77 & 1,52 & $-2,85$ \\
$\Delta \delta=\left(\delta-\delta_{\text {тхм }}\right)$ & 0,03 & $-0,04$ & 0,06 & $-0,02$ & $-0,1$ \\
\hline Пиридин & - & - & - & 1,52 & $-2,27$ \\
$\Delta \delta$ & - & - & - & $-0,02$ & 0,48 \\
\hline Ацетонитрил & 8,84 & 8,05 & 7,78 & 1,54 & $-2,81$ \\
$\Delta \delta$ & 0,04 & $-0,01$ & 0,07 & 0,00 & $-0,06$ \\
\hline Ацетон & 8,88 & 8,12 & 7,91 & 1,55 & $-2,70$ \\
$\Delta \delta$ & 0,08 & 0,06 & 0,20 & 0,01 & 0,05 \\
\hline ДМАА & 8,88 & 8,11 & 7,80 & 1,54 & $-2,71$ \\
$\Delta \delta$ & 0,08 & 0,05 & 0,09 & 0,00 & 0,04 \\
\hline ДМФА & 8,88 & 8,10 & - & 1,55 & $-2,73$ \\
$\Delta \delta$ & 0,08 & 0,04 & - & 0,01 & 0,02 \\
\hline ДО & 8,81 & 8,11 & 7,79 & 1,52 & $-2,77$ \\
$\Delta \delta$ & 0,01 & 0,05 & 0,08 & $-0,02$ & $-0,02$ \\
\hline
\end{tabular}

Анализ данных показывает, что сигналы $\beta$-пиррольных и фенильных протонов порфирина I претерпевают небольшой сдвиг в слабое поле (исключение составляют орто-протоны фенильных колец в ДМСО и ацетонитриле). Учитывая отсутствие в этих фрагментах молекул потенциальных центров для образования Н-связей, можно сделать вывод, что эти смещения сигналов связаны с неспецифической сольватацией порфирина, учитывая высокую полярность этих растворителей.

В то же время сигналы от внутрициклических протонов (NH) в электронодонорных растворителях смещаются как в слабое поле (П, АЦ, ДМФА, ДМАА), так и в противоположном направлении (ДМСО, АН, ДО) относительно растворов в TХМ. Для того чтобы выяснить, связано ли это с образованием Н-комплексов (I...ЭД), были получены концентрационные и температурные зависимости 


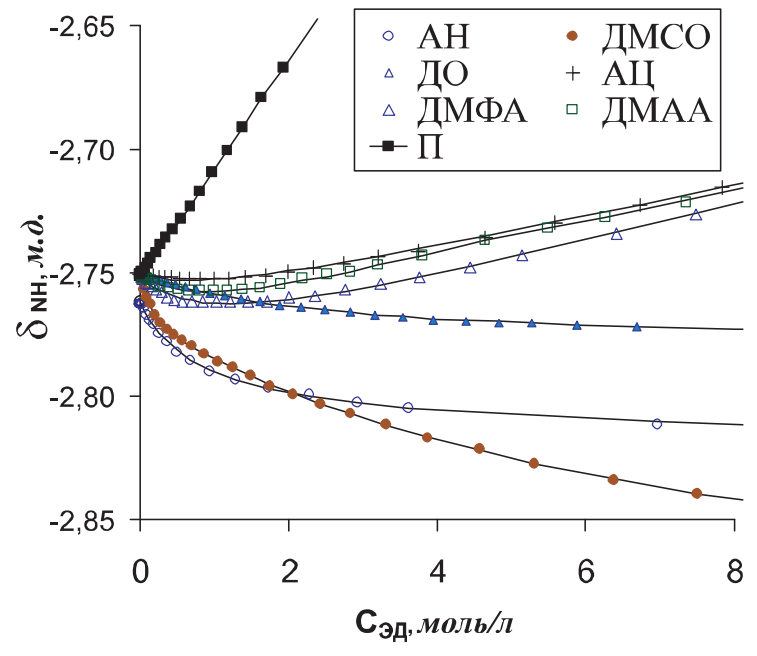

Рисунок 1. Зависимости химического сдвига протонов $\mathrm{NH}$ тетра(3,5-ди-трет-бутилфенил)порфина (0,01 М) от концентрации электронодонорного компонента в смеси ЭД+ТХМ при 298 К.

химических сдвигов NH-протонов в смешанных растворителях ТХМ+ЭД, представленные на Рисунке 1.

Анализ этих зависимостей показывает, что добавление небольших количеств электронодонорного растворителя приводит к достаточно резким изменениям химических сдвигов. Такой ход кривых может являться следствием образования Н-комплексов I...ЭД за счет водородных связей с участием внутрициклических групп -NH тетра(3,5-ди-трет-бутилфенил)порфина и электронодонорных фрагментов $(\mathrm{CO}, \mathrm{CN})$ растворителей. ${ }^{[13,14]}$ Следует отметить различный характер зависимостей для разных растворителей. Особенно это касается участков кривых, относящихся к большим концентрациям сольватирующего растворителя, где наблюдается линейная зависимость ХС от концентрации ЭД. При этом близкое поведение демонстрируют ацетон, диметилацетамид и диметилформамид, для которых наблюдается положительный наклон зависимостей $\delta=f(C)$ в области больших концентраций. Линейный характер зависимости химического сдвига NH-протонов порфирина I от концентрации пиридина в растворе во всем диапазоне указывает на отсутствие образования водородной связи $\mathrm{NH} \cdots \mathrm{N}$ для этого растворителя. Возможно, это связано со стерическими затруднениями, учитывая геометрию порфирина I и пиридина. Между тем, резкое изменение $\Delta \delta$ в пиридине по сравнению с ТХМ (Таблица 1) свидетельствует, по-видимому, о заметной сольватации. Принимая во внимание не очень высокую полярность и ароматический характер пиридина, можно предположить, что подобное поведение резонансного сигнала $\mathrm{NH}$ обусловлено сильным влиянием магнитно-анизотропных молекул пиридина, находящихся в сольватной оболочке макроцикла, на химический сдвиг NH. Необходимо отметить также, что в работе ${ }^{[15]}$ отмечено образование $\pi$-комплексов порфирин - пиридин.

Для определения термодинамических параметров Н-комплексов было проведено моделирование концентрационных зависимостей химических сдвигов ${ }^{1} \mathrm{H}$ ЯМР $\left(\delta_{\mathrm{NH}}\right)$ при варьировании температуры.
Рассматривался равновесный процесс присоединения электронодонора к макрогетероциклу:

$$
\begin{aligned}
& \mathbf{I}+\text { ЭД } \Leftrightarrow(\mathrm{I} \cdots \text { ЭД }), \\
& K_{\mathrm{k}}=\left[M_{\mathrm{K}}\right] /\left[M_{\mathrm{I}}\right] \cdot\left[M_{\text {эд }}\right],
\end{aligned}
$$

где $K_{\mathrm{k}}$ - константа устойчивости комплексов; $M_{\mathrm{K}}, M_{\mathrm{I}}$, $M_{\text {эд }}$ - молярные концентрации комплекса порфирина с электронодонором, порфирина I и электронодонора, соответственно.

Химический сдвиг $\delta_{\mathrm{NH}}$ I может быть выражен как:

$$
\delta_{\mathrm{NH}}{ }^{\text {pacu }}=\delta_{0} \cdot N_{\mathbf{0}}+\delta_{\mathbf{K}} \cdot N_{\mathrm{K}}
$$

где $\delta_{0}, \delta_{\mathrm{K}}-$ химические сдвиги протонов «несвязанного» октазамещенного порфирина и в комплексе с электронодонором, соответственно; $N_{0}, N_{\mathrm{K}}$ - мольные доли компонентов.

Совместное решение уравнений (1)-(3) позволяет рассчитать $\delta_{\mathrm{NH}}^{\text {расч }}$ для каждой концентрации ЭД.

C помощью процедуры МНК-минимизации

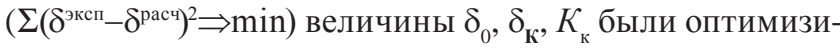
рованы до наилучшего соответствия экспериментальных и теоретических химических сдвигов. На основании температурных зависимостей $(298 \mathrm{~K}<\mathrm{T}<328 \mathrm{~K})$ логарифмов констант устойчивости $\left(K_{\mathrm{k}},\right)$ рассчитаны энтальпии комплексообразования.

Анализ полученных результатов (Таблица 2) показывает, что для растворителей, у которых Н-комплекс I․ㄱ образован с участием свободных электронных пар кислорода, константа устойчивости возрастает в

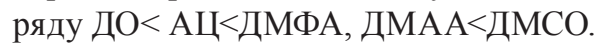

При этом величины логарифмов констант линейно связаны с основностью $(B)^{[16]}$ карбонилсодержащего сольватирующего компонента раствора (АЦ, ДМФА, ДМСО, ДМАА), т.е. для соединений с близкой структурой электронодонорного фрагмента, непосредственно участвующего в образовании Н-связи (Рисунок 2). Изменение природы донорной группы (ДО, АН) приводит к выпадению из прямолинейной зависимости.

Для выяснения особенностей структуры Н-комплексов были использованы квантово-хими-

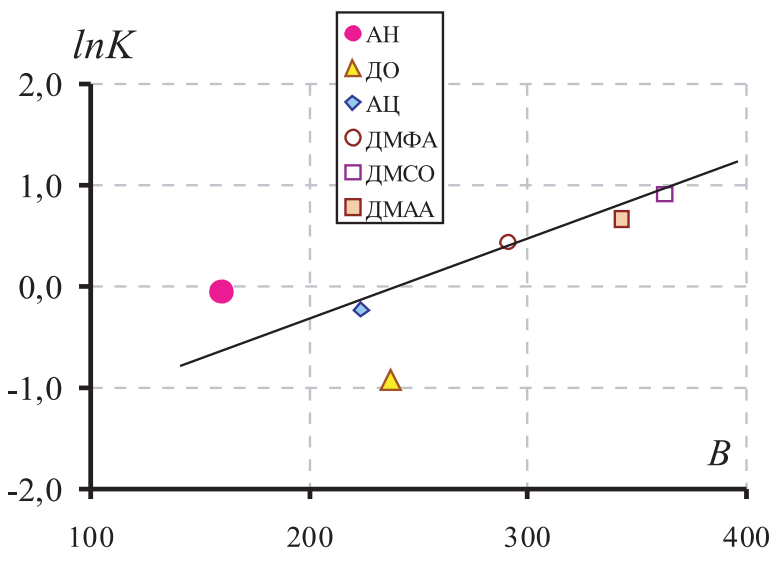

Рисунок 2. Зависимости логарифмов констант устойчивости комплексов $\mathrm{\cdots}$ ЭД от основности $B\left(\mathrm{~cm}^{-1}\right)$ растворителя. ${ }^{[16]}$ 


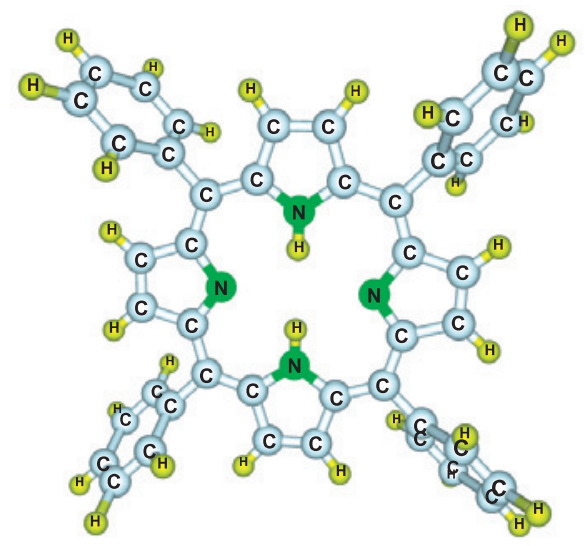

II $\left(\Delta H_{f}=361,27\right.$ ккал· моль $\left.{ }^{-1}\right)$

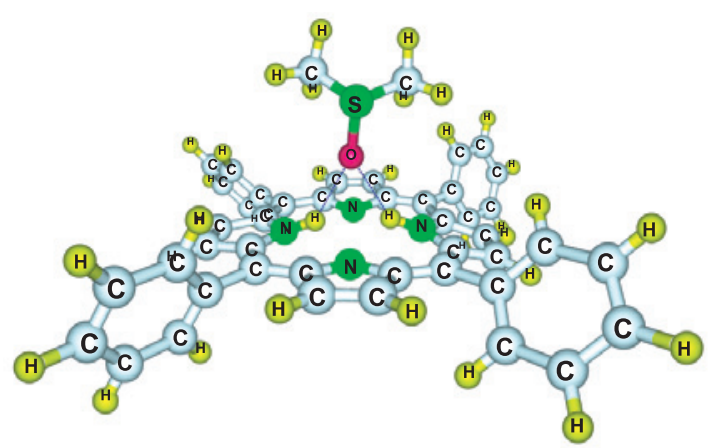

II‥ДМСО $\left(\Delta H_{f}=320,51\right.$ ккал·моль $\left.{ }^{-1}\right)$

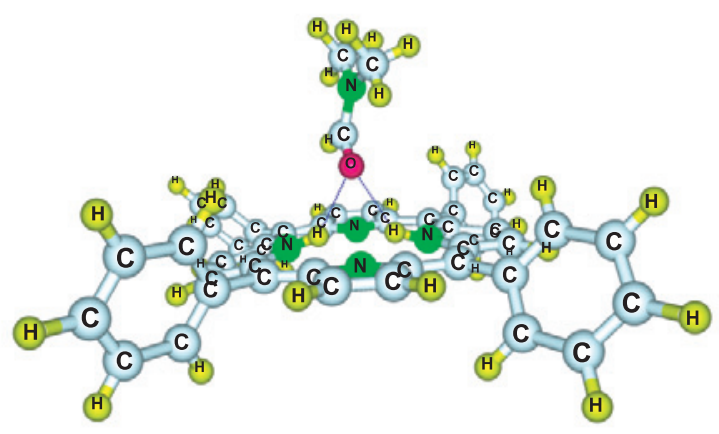

II'.ДМФА $\left(\Delta H_{f}=323,70\right.$ ккал·моль $\left.{ }^{-1}\right)$

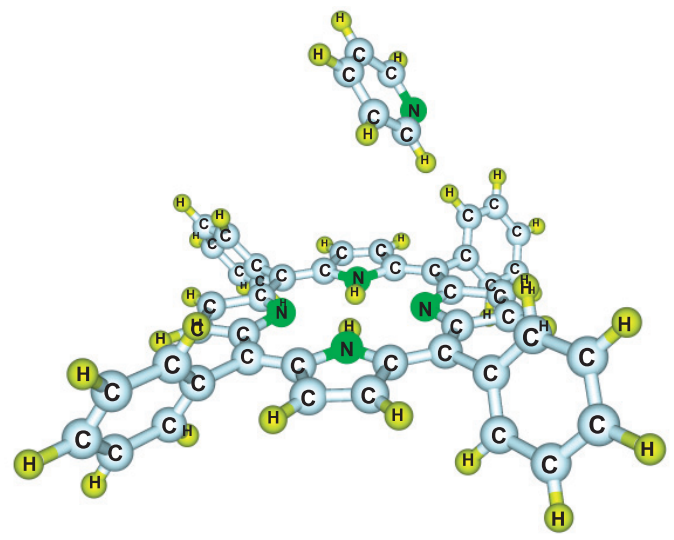

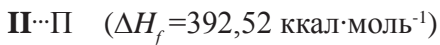

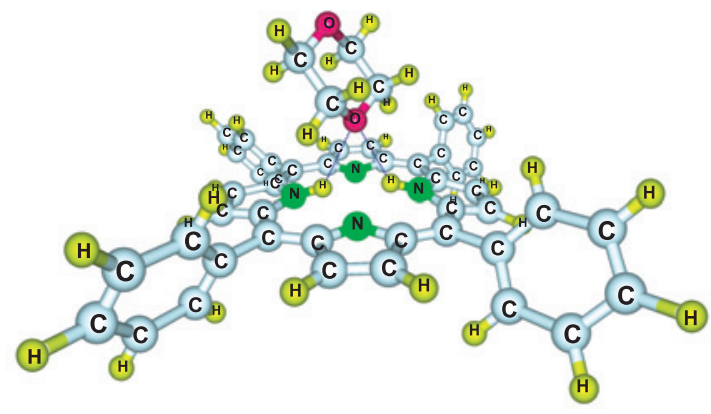

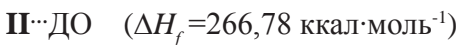



II'*AЦ $\left(\Delta H_{f}=311,61\right.$ ккал·моль $\left.{ }^{-1}\right)$

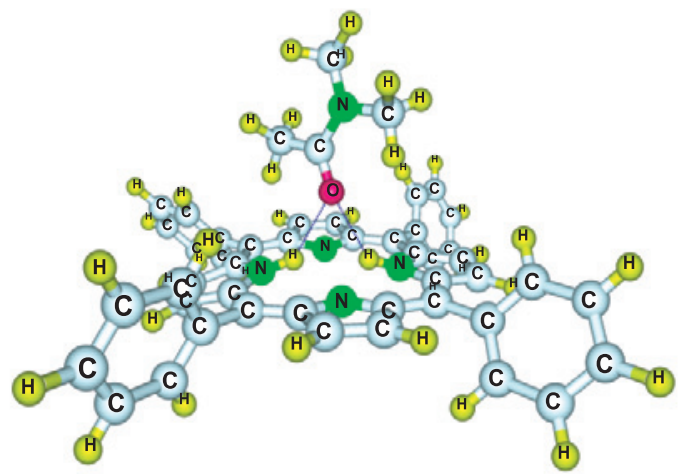

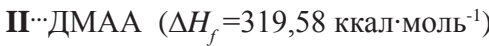

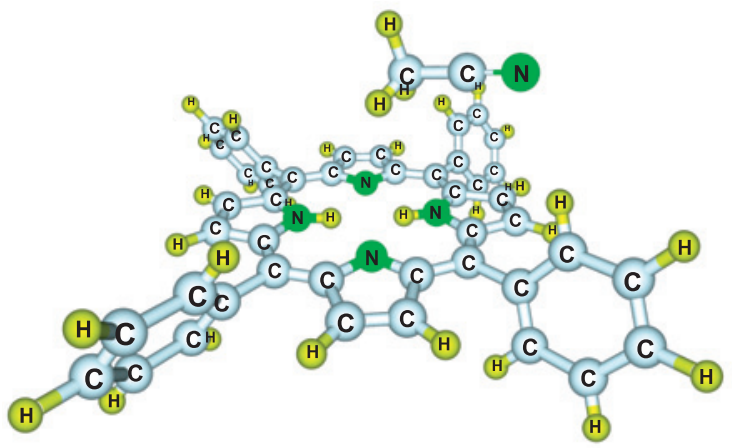

II $\cdots$ AH $\quad\left(\Delta H_{f}=379,55\right.$ ккал'моль $\left.{ }^{-1}\right)$

Рисунок 3. Оптимизированные АМ1 структуры Н-комплексов тетрафенилпорфин II ㅋ. Э. 
ческие расчеты с использованием полуэмпирического метода АM1. ${ }^{[17]}$

На Рисунке 3 представлены оптимизированные структуры тетрафенилпорфина (II) (mpет-бутильные заместители I в целях рационализации расчетного времени опущены) и его Н-комплексов с исследуемыми растворителями.

Образование Н-комплексов ТФП с участием АЦ, ДМСО, ДМФА, ДМАА и ДО приводит к искажению плоской структуры макроцикла. Плоскости пиррольных колец отклоняются от плоскости, в которой расположены экзоциклические атомы углерода ТФП на угол порядка 12-14 градусов. Акопланарными становятся и пирролениновые кольца (4-6 градусов). При этом значительное влияние оказывают ДМСО, ДМФА и ДМАА, характеризующиеся наибольшими из всех ЭД константами устойчивости Н-комплексов. Анализ геометрии комплексов показывает, что Н-связи $\mathrm{NH}^{\cdots} \mathrm{O}$ с участием обеих свободных электронных пар ЭД практически равновероятны, что делает возможным образование «трехцентровой» водородной связи.

Таблица 2. Химические сдвиги $\left(\delta_{K}\right)$, константы устойчивости $\left(K_{\mathrm{k}}\right)$ и энтальпии $\left(\Delta H_{\mathrm{k}}\right)$ Н-комплексов (Iㅋ.ЭД), рассчитанные по данным ${ }^{1} \mathrm{H}$ ЯМР и АM1 $\left(\Delta \Delta H_{f}\right)$ при $298 \mathrm{~K}$.

\begin{tabular}{ccccc}
\hline ЭД & $\begin{array}{c}\delta_{\mathrm{K}}, \\
\text { м.Д. }\end{array}$ & $\begin{array}{c}K_{\mathrm{k}}, \\
\text { л } \cdot \text { моль }^{-1}\end{array}$ & $\begin{array}{c}\Delta H_{\mathrm{k}}, \\
\text { ккал } \cdot \text { моль }^{-1}\end{array}$ & $\begin{array}{c}\Delta \Delta H_{f}^{*}, \\
\text { ккал } \cdot \text { моль }^{-1}\end{array}$ \\
\hline АН & $-2,81$ & 1,0 & $-2,1$ & $-1,02$ \\
ДО & $-2,78$ & 0,4 & $-0,7$ & $+0,49$ \\
АЦ & $-2,77$ & 0,8 & $-2,2$ & $-0,46$ \\
ДМФА & $-2,78$ & 1,7 & $-2,4$ & $-0,67$ \\
ДМСО & $-2,79$ & 2,5 & $-2,3$ & $-1,36$ \\
ДМАА & $-2,77$ & 1,9 & $-1,4$ & $-0,33$ \\
\hline \multirow{5}{*}{ * $\Delta H_{f}=\left[\Delta H_{f}\right.$ (компл.) - $\left[\Delta H_{f}(\mathbf{I I})+\Delta H_{f}\right.$ (раств.)]- для } \\
\hline \multicolumn{5}{c}{ тетрафенилпорфина (II) }
\end{tabular}

Анализ термодинамических характеристик образования комплексов IIㅋЭД (Таблица 2, Рисунок 3) подтверждает сделанные предположения. Так, величины теплоты образования $\left(\Delta H_{f}\right)$ супермолекул тетрафенилпорфина с АЦ, ДМСО, ДМФА, ДМАА достаточно близки, что указывает на сходный характер Н-связи СОNH для этих систем. В то же время, возрастание $\left(\Delta H_{f}\right)$ с участием ацетонитрила и особенно пиридина по сравнению с индивидуальным макроциклом подтверждает вывод о неэффективности связывания тетрафенилпорфина и данных растворителей за счет водородной связи $\mathrm{NH} \cdots \mathrm{N}$. Кроме того, для этих систем не наблюдаются искажения макроцикла II (Рисунок 3).

При рассмотрении термодинамических характеристик обнаружено удовлетворительное соответствие экспериментальных (ЯМР), и расчетных (AM1) данных (Таблица 2). Следует отметить, что равенства абсолютных величин энтальпий Н-комплексов $\left(\Delta H_{\text {к }}\right.$ и $\left.\Delta \Delta H_{f}\right)$ не наблюдается. Тем не менее, несмотря на различные условия расчета термодинамических величин комплексов (раствор и газовая фаза) сохраняются аналогичные тенденции изменения в зависимости от природы растворителей. Таким образом, совместное использование полуэмпирических расчетов и данных спектроскопии ЯМР позволило установить структуру и оценить устойчивость комплексов с водородной связью октазамещенного тетрафенилпорфина (I) с электронодонорными растворителями.

Благодарность. Работа выполнена при финансовой поддержке грантов РФФИ 05-03-32738а и 05-03-33003а.

\section{Список литературы}

\section{References}

1. Berezin B.D., Enikolopyan N.S. In Porfiriny: Struktura, Svoyst$v a$, Sintez [Porphyrins: Structure, Properties, Synthesis] (Enikolopyan N.S., Ed.). Moskva, Nauka, 1985, p. 334. (in Russ.).

2. Koifman O.I., Ageeva T.A. Strukturnye Tipy Porfirinov [Structural Types of Porphyrins], in Uspekhi Khimii Porfirinov [The Advances in Porphyrin Chemistry]. Vol. 1. St. Petersburg, NII Khimii SpbGU, 1997, 6-26. (in Russ.).

3. The Porphyrin Handbook. Vols. 1-10 (Kadish K.M., Smith K.M., Guilard R., Eds.) Amsterdam, Academic Press, 19992003.

4. Aleksandriiskii V.V., Islyaikin M.K., Shutov I.G., Zhurko G.A., Burmistrov V.A. Rus. J. Phys. Chem. 2005, 79, Suppl. 1, S130-S134.

5. Aleksandriiskii V.V., Islyaikin M.K., Burmistrov V.A. Zh. Fiz. Khimii 2007, 81, 2000-2005. (in Russ.).

6. Hynninen P.H., Lötjönen S. Biochimica et Biophysica Acta (BBA) - Bioenergetics 1993, 1183, 381-387.

7. Koifman O.I., Berezin B.D. In Problemy Sol'vatatsii i Kompleksoobrazovaniya [The Problems of Solvation and Complex Formation]. Mezhvuzovskii sbornik, 1978, 124-132. (in Russ.).

8. V’yugin A.I. Termodinamika Prozessov Rastvoreniya i Solvatatsii Prirodnykh i Sinteticheskikh Porfirinov i ikh Kompleksov [Thermodinamics of Dissolution and Solvation of Natural and Sythetical Porphyrins and Their Complexes], in Rastvory Neelekrolitov v Zhidkost'akh [Nonelectrolite Solutions in Liquids] (Nikiforov M.Yu., Al'per G.A., Durov V.A., etc., Eds.). Moskva, Nauka, 1989, p. 263. (in Russ.).

9. Antina E.V., V'yugin A.I., Krestov G.A. Zh. Fiz. Khimii 1990, 64, 2000-2002. (in Russ.).

10. Semeikin A.S., Koifman O.I., Berezin B.D. Khimiya Geterotsickl. Soed. 1986, 6, 798-801. (in Russ.).

11. Bagno A. Progress in Nuclear Magnetic Resonance Spectroscopy 2005, 47, 41-93.

12. Vaysberger A. Organicheskie Rastvoriteli [Organic Solvents]. Moskva, Mir, 1976, p. 447. (in Russ.).

13. Medforth C.J. NMR Spectroscopy of Diamagnetic Porphyrins, in The Porphyrin Handbook (Kadish K.M, Smith K.M., Guilard R., Eds.). Vol. 5. Academic Press, New York, 2000, 1-80.

14. Limbach H.H. J. Chem. Phys. 1983, 26, 410-431.

15. Lebedeva N.Sh., V'yugin A.I., Pavlycheva N.A. Zh. Fiz. Khimii 2002, 76, 1735-1739. (in Russ.).

16. Abboud J.-L.M., Notario R. IUPAC, Pure Appl. Chem. 1999, 71,645

17. Dewar M.J.S., Zoebisch E.G., Healy E.F., Stewart J. J. P. J. Am. Chem. Soc. 1985, 107, 3902. 